\title{
NEW ENGINEERING APPROACH FOR THE DEVELOPMENT AND DEMONSTRATION OF A MULTI-PURPOSE PLATFORM FOR THE BLUE GROWTH ECONOMY
}

\author{
F. Lagasco \\ RINA Consulting S.p.A. \\ Genova, Italy
}

A. Mariotti

Fincosit s.r.l.

Genova, Italy

T. Atack

Sagro Aquaculture Ltd Limassol, Cyprus

\author{
A. Santoro \\ Wavenergy.it s.r.l. \\ Reggio Calabria, Italy
}

\author{
S. Muggiasca \\ Politecnico di Milano \\ Milano, Italy
}

\author{
E. Safier \\ Safier Ingenierie SaS \\ Paris, France
}

Department of Naval Architecture, Ocean and Marine Engineering, University of Strathclyde,

Glasgow, UK

\author{
F. Arena \\ Natural Ocean Engineering \\ Laboratory (NOEL), Mediterranea \\ University of Reggio Calabria \\ Reggio Calabria, Italy \\ P. Tett \\ The Scottish Association for \\ Marine Science lbg \\ Dunbeg Oban, UK \\ F. F. Salcedo \\ Fundacion Tecnalia Research \& \\ Innovation \\ Bilbao, Spain
}

G. Brizzi

Chlamys s.r.l.

Trani, Italy

S. Bourdier

Ecole Centrale de Nantes, Experimental facilities for Hydrodynamics and Ocean

Engineering

Nantes, France

\section{ABSTRACT}

Aquaculture is currently the fastest growing food sector in the world and the open oceans are seen as one of the most likely areas for large-scale expansion [1], [2], [3]. The global demand for seafood is continuing to rise sharply, driven by both population growth and increased per capita consumption, whilst wild-capture fisheries are constrained in their potential to produce more seafood. A recently funded EC project, the Blue Growth Farm - BGF (GA n. 774426, $1^{\text {st }}$ June $2018 \div 30^{\text {th }}$ September 2021) aims at contributing to this world need with an original solution. The Blue Growth Farm proposes an efficient, cost-competitive and environmentally friendly multi-purpose offshore farm concept based on a modular floating structure, moored to the seabed, meeting requirements of efficiency, costcompetitiveness and environmental friendless, where automated aquaculture and renewable energy production systems are integrated and engineered for profitable applications in the open sea. In the present paper, the overall engineering approach developed to carry out the research work is presented, described and justified. Different technical and scientific challenges are addressed through an integrated industrial engineering design approach, where all disciplines are tuned to achieve the Blue Growth Farm main targets, represented by: i) guaranteeing expected nominal fish production thanks to advanced automation and remote control capabilities; ii) minimizing the pollution introduced at marine ecosystem level when exploiting the marine natural resources, whilst increasing the social acceptance and users community agreement; iii) maximizing the electricity production in the Blue Growth Farm potential installation area ecosystem to provide energy supply to the onboard electrical equipment and to dispatch the extra produced electric energy to the land network. Preliminary engineering design results are promising to demonstrate effective increase of safety and efficiency by reducing on-board human effort and consequently risks at offshore, thus to make commercial-scale open ocean farming a reality. 
The present paper is introductory to other Blue Growth Farm project papers submitted at OMAE2019 [4], [5], [6].

\section{INTRODUCTION}

Long-term survivability of floating structures has been already demonstrated by marine and offshore oil industries over many decades. However, the economics that allowed the deployment of offshore rigs have yet to be demonstrated for floating multi-purpose offshore platforms. In this light, the Blue Growth Farm project lays a foundation stone to meet this endeavour by developing an efficient, cost-competitive and environmentally friendly multi-purpose offshore farm design where aquaculture and renewable energy production systems are integrated and engineered for applications in the open sea. A considerable effort is placed to demonstrate the environmental and economic sustainability of the proposed system. For this reason the environmental concerns are addressed since the conceptual phase and pursued throughout the project development, testing and validation in order to guarantee having effectively minimized impacts on the ecosystem, as well as having set the bases for the long-term monitoring procedures. This process is crucial to enable the design to embrace any likely issues that can be engineered or mitigated once innovative efficient technologies come to market. For these reasons, the conceptual mind-set at the base of the Blue Growth Farm approach is then based on threefold concern: i) minimizing the pollution introduced at marine ecosystem level; ii) maximizing the electricity production in the Blue Growth Farm potential installation area ecosystem; iii) supporting knowledge transfer and exchange via structured diffusion of information and knowledge about scientific and technological enhancements achieved by the proposed multipurpose offshore platform for a wider social acceptance and a synergy development with the actual sea users.

Different innovative designs for multi-use offshore platforms have been recently presented and compared in their various applications [7] [8]. In particular, the Blue Growth Farm project benefits from the multi-use economic feasibility issued in the $\mathrm{H}_{2}$ Ocean project (the only one dealing with wind, wave and aquaculture among those financed by EC under the FP7 call "Ocean of Tomorrow"), but it relies on the knowledge produced within the project because of different kind of infrastructure technologies and strategies involved. The environmental monitoring plan for the platform full operational life is expected to valuably contribute to demonstrate the environmental sustainability of the farm.

\section{THE BLUE GROWTH FARM (BGF) SYSTEM}

The Blue Growth Farm project deals with the significant challenge of providing integrated design solutions for multipurpose offshore platform, which successfully combines aquaculture and renewable energy production for environmental and economic sustainable deployment in open sea sites. The 3D picture of the proposed Blue Growth Farm is represented in the following Figure 1. It consists of a concrete caissons based protective structure, optimized in the foot-print, suitably oriented in the prevailing sea waves, buoyant at a $20 \mathrm{~m}$ average draft and moored in $100 \div 200 \mathrm{~m}$ water depths.

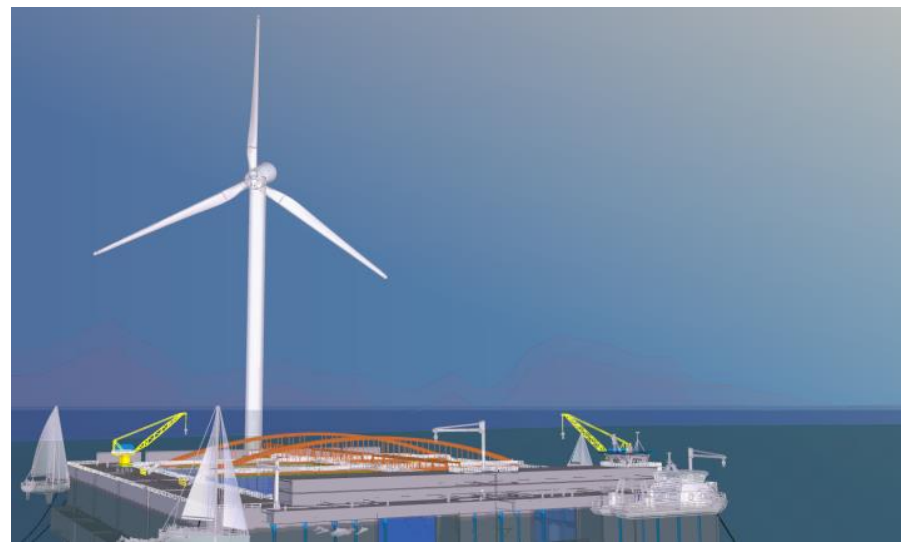

Figure 1. The Blue Growth Farm full scale configuration

The proposed aquaculture size for the Blue Growth Farm is characterized by 6 net cages, $35 \mathrm{~m}$ depth, for an overall fish production of 2.000 tons/year. The net cages may be directly attached to the structure, whilst sinker structure weights at the bottom maintain them in position. The selected shape of the platform is such to maximise the dilution of effluents resulting from farm biomasses, thanks to the transparent side located in opposite position to the prevailing wave motion direction. The design of the renewable energy production systems includes: 1) a commercial DTU $10 \mathrm{MW}$ wind turbine [9]; 2) a number of wave energy converter (WEC) turbines placed on favourable platform sides for wave energy power extraction (floating version of the REWEC3 patent, which is a particular type of Oscillating Water Column (OWC) incorporated into a traditional vertical breakwater of monolithic reinforced concrete structure type [10] (see Figure 2).

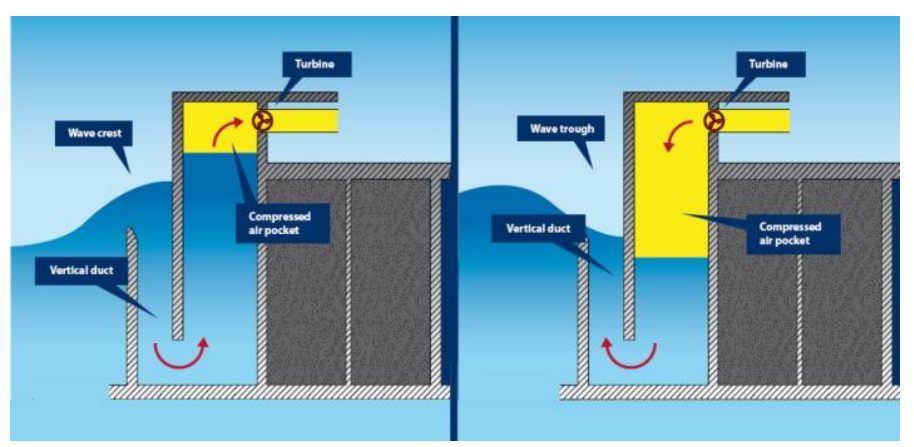

Figure 2. Scheme of the modified REWEC3 model for floating applications

The automation and control system enables management on deck and by remote of all platform operations as well monitoring of all integrated technologies. Once operators are on-board and access the Automation \& Control room, they are allowed from remote to assume the master, and then to safely carry out the planned tasks, leaving to remote the monitoring configuration only. The Surveillance \& Security system is in 
charge of providing the remote control with a general view of the platform condition and operations, as well as a picture of events related to the maritime domain, thus contributing to the maritime transport \& blue border surveillance needs.

The Blue Growth Farm overall system composition is introduced by the block diagram in Figure 3, whilst each component is described in the following:

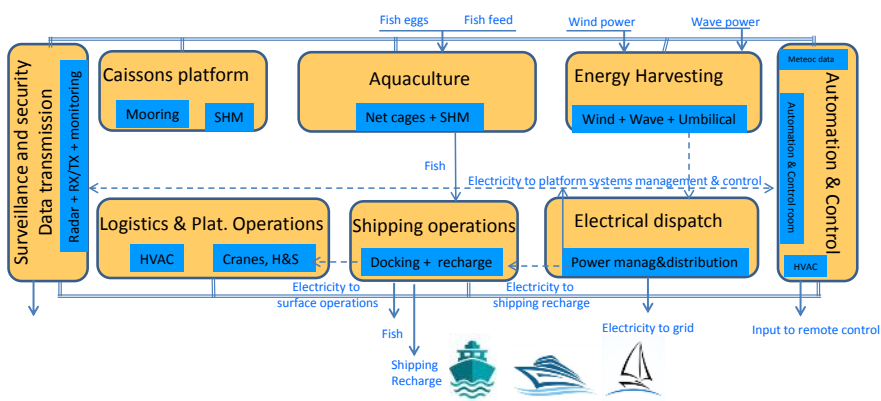

Figure 3. The Blue Growth Farm system composition

Automation and Control: Design of an automation architecture fully integrated in the platform monitoring and control system is one of the challenges identified for the Blue Growth Farm project. The overall BGF Automation and Control system composition as identified in the preliminary engineering design is described in Figure 4. The overall control system centrally integrates the information of the sub-systems that compose the platform (aquaculture, wind-turbine, WEC, energy management and dispatching system, automation and control, security and surveillance systems). The overall monitoring / control system makes use of the data coming from each of the sub-systems as well as display alarms, faults detected and structural safety monitoring measurements. The control system also includes security checks, on the basis of security equipment and procedures established for the platform operations under safe conditions.

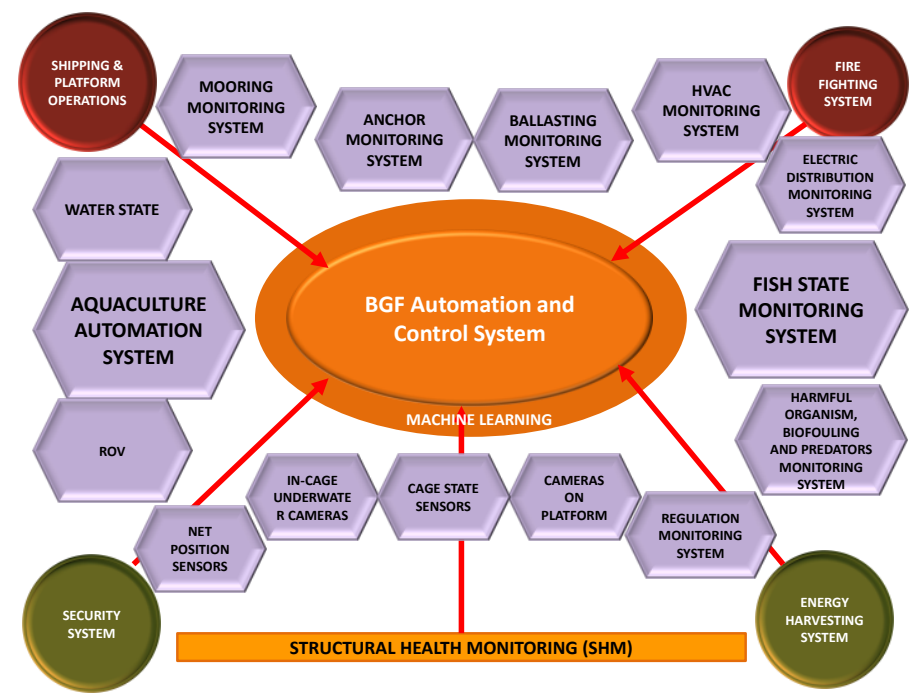

Figure 4. The Blue Growth Farm automation and control system composition
Additionally, on the basis of wind and wave energy harvesters' characteristics, their respective power delivery has to be optimized in order to reduce power losses, whilst power quality issues are also related to smoothness of the power delivery.

The automation and control functions are managed in the BGF control room placed in the platform aft side (Figure 5).

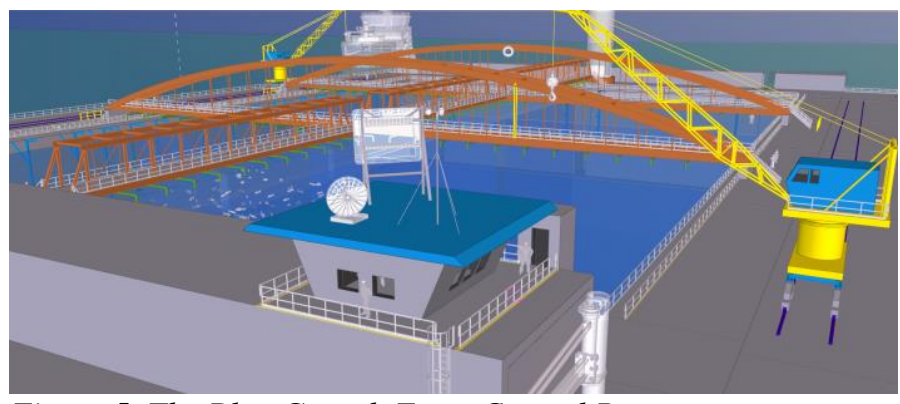

Figure 5. The Blue Growth Farm Control Room

Floating caissons based platform: the semi-submersible type floating platform conceived for the Blue Growth Farm is based on industrialised modular concrete caissons technology for typical marine applications. This solution enables to deploy a suitable protective base structure to adequately host aquaculture production system as well as the envisaged renewable energy production devices. Implementation of the wave energy converter devices additionally help to download wave forces effects on the platform structure thanks to the partial wave energy absorption and transformation at impact [11]. Because of the modular composition of the concrete caissons and in order to minimize construction costs, an optimized engineering process to deploy each module in the installation bay, to connect rigidly each other up to the final composition of the selected platform final shape before it is moved by tugs up to the final destination site, has been developed. Characterisation of the overall behaviour of the connected caisson modules, as well as of the overall behaviour of the connected assembly is a key $R \& D$ challenge and it is object of experimental testing and validation in the project development. The most appropriate Structural Health Monitoring (SHM) technology has been considered to implement a full life database of measured data, to feed suitable models to interpret the differential displacements and then have an assessment of residual life due to operative conditions. The BGF SHM is based on Fibre Bragg Grating (FBG) technology sensors, which work as optical strain gauges and allow measuring the structural and/or thermal deformation by means of an appropriate analysis of the optical signal back scattered by a diffraction grating photo-induced in the body of a fibre.

Aquaculture: The presence of the protective service platform opens up opportunities for system automation, management and monitoring otherwise unavailable to offshore fish farms where the extreme sea conditions prevent standard feed/service barges being deployed. In addition, many general production activities that are currently carried out manually 
from workboats stationed alongside the aquaculture installation can be sited on the platform with the support of service cranes, ROVs, automated net cleaners, mortality collection/processing equipment etc. The installed renewable energy production capacity also enables optimal lighting of the fish pens at all times in order to improve growth and reduce fish maturation levels. Meanwhile, other routine operations, such as fish stocking and harvesting can still be effected in the usual way via wellboat moored externally to the platform.

Traditional cage farming operations are generally timeconsuming and expensive. To this extent data analytics technology suitably supports all phases of the production process. With specific reference to the different stages of aquaculture production, from stocking to harvest, optical sensors, machine vision and acoustic systems give the possibility of developing faster, cheaper and non-invasive methods for in situ production efficiency and product quality improvement and by reducing the risk of losses due to disease or escape.

In particular, the following needs are covered in the BGF monitoring configuration (Figure 6):

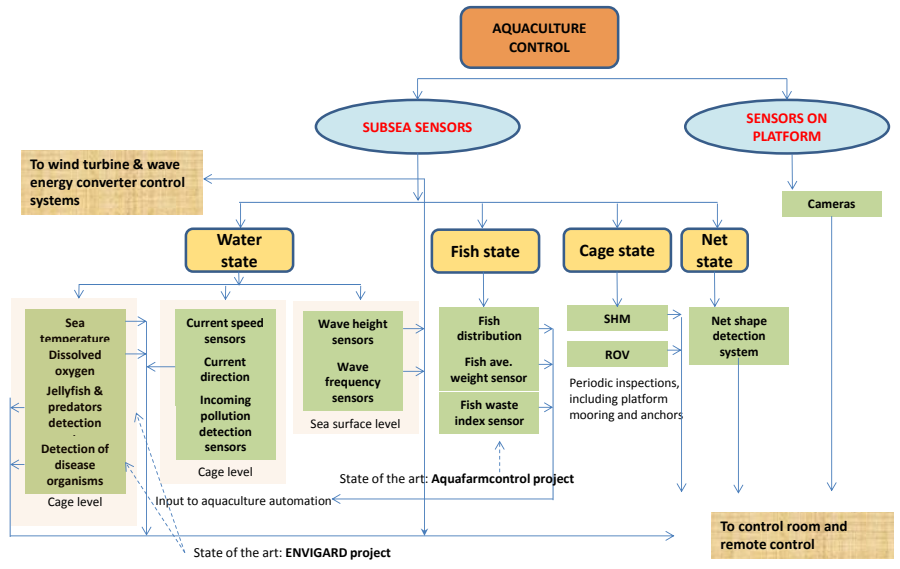

Figure 6. The Blue Growth Farm aquaculture sensing

a) a highly automated fish feed management and stock performance monitoring system with feedback loops to the various installed sensor systems; b) continuous automated monitoring of the fish pen environment (i.e. temperature, oxygen, chlorophyll, ammonia etc.) to optimize farm operations, maintain fish welfare, and to assess fish reaction to different farming operations and environmental influences; c) underwater video observation and acoustic stock position and movement data to allow early disease diagnosis and any occurrence of predator attack; d) constant monitoring of mortality levels via underwater cameras and by monitoring the numbers of fish passing through the automatic mortality collection system to give early indications of a fish health or water quality problem; e) general aquaculture facility SHM; f) an automated security system to reduce the risk of theft of the stocks. All data collected and reported to the control room is also relayed to the remote control operator centre (Figure 7) flagging of any alarms or abnormal system state conditions.

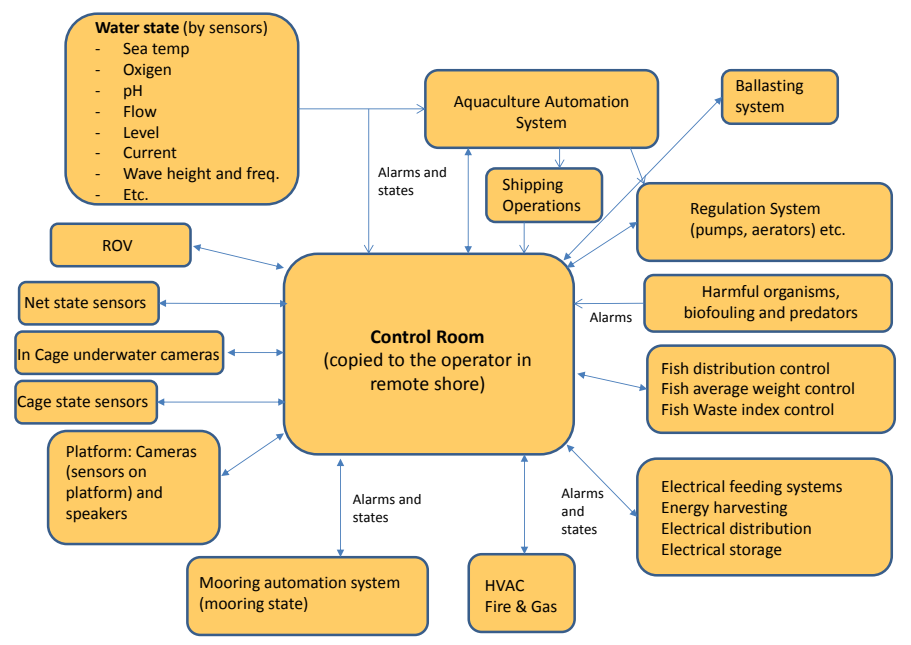

Figure 7. The Blue Growth Farm data management system

Sensors and SCADA data, control systems and automation feedbacks are also object of processing in terms of Machine Learning techniques such to enhance the control ability by improving knowledge from information and data coming from different physical sources are implemented (Figure 8).

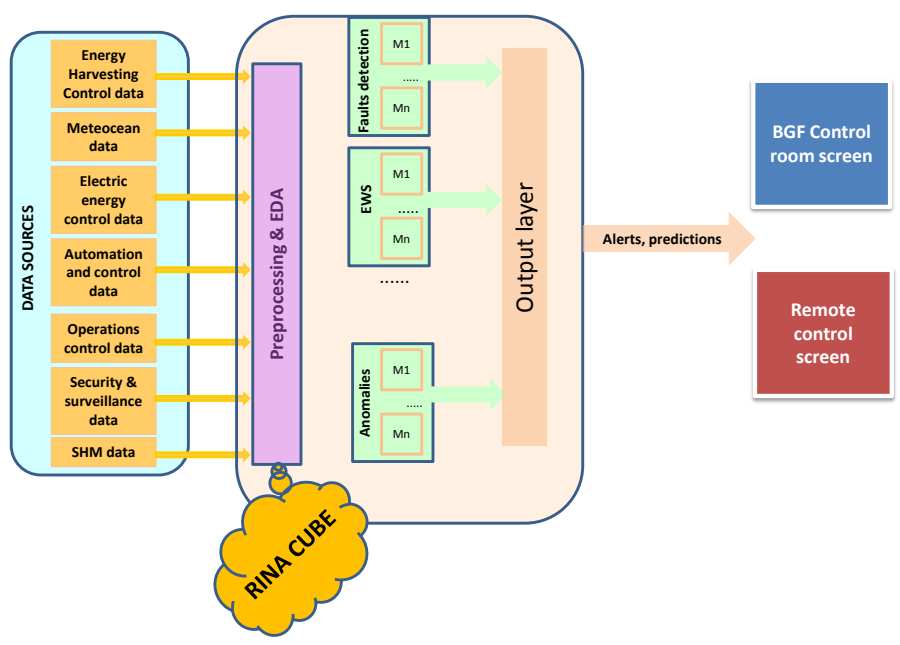

Figure 8. The Blue Growth Farm data analytics process

Machine Learning (ML) approaches require very few prior assumptions for input variables compared to classical statistical models, and offer advantages in processing outliers. In an initial phase, a set of models are trained in order to be able to use them to perform certain tasks like predicting a response that can be from a fault prediction to an alert or an early warning signal. Once these models are trained, they are capable of generalizing behaviours from information provided in the form of a datasets. In a second phase, given a sample coming from the data sources, the trained models return the predicted value. Being these measurements ordered in time, they compose multivariate time series and thanks to the existence of patterns, trends and cyclic components inference for future values of the sensors are achievable.

In particular, the RINACube digital platform is employed to process BGF data. RINACube develops solutions built 
around the digitalisation of the physical asset (digital twin) and on the related operating and performance data. The RINACube software operates in cloud with large amounts of data coming from operation, maintenance and automation systems, as well as other management and technology systems, and can also integrate and manage manual inputs, unstructured data and data from external sources (satellite, external databases etc.).

Energy Harvesting: The offshore energy production system proposed for the Blue Growth Farm project maximises the exploitation of natural resources at offshore by hybridising an integrated customizable assembly. The BGF system design considers a smart control strategy of the hybrid (wind\&wave) energy harvesting platform. Objectives of the control strategy are to smooth the power production whilst balancing the absorbed energy and stabilisation of floating platform to keep it operationally functional and under safe conditions. The BGF energy production control for the combined system exploits the R\&D already developed ([12], [13], [14], [15], [16]), and it is optimised by modelling different control strategies acting on both wind turbine and WECs. Outcomes are then compared in terms of power output smoothness and platform displacements, on the basis of site resources wind turbine \& WEC devices characteristics. A more precise estimate of the power delivery and the quality of power production is then expected to be achieved.

Surveillance and security: an integrated system of radar and cameras provides the remote control centre with a real time picture of activities and vessels approaching the multipurpose platform. The local navigation surveillance system is potential to become a distributed network if other installations adopt the proposed technology. This capacity is in line with EU policy and strategies for maritime border control. In particular, the proposed system enables data acquisition of the platform surroundings and transmission in accordance to international standards. In particular, a twofold approach to R\&D challenges in the Blue Growth Farm technologies has been conceived: i) optimised integration of Surveillance Radars, AIS and longdistance cameras to provide an accurate surveillance of maritime traffic and to identify eventual unexpected events (accidental or deliberate actions). Adequate $\mathrm{R} \& \mathrm{D}$ is to find reliable integrated solution as a result of cost, performance and durability to harsh environment trade off analysis; ii) smart security network cameras to implement access control of operators and surveillance of accuracy in carrying out tasks in safe conditions, thus promoting adequate behaviour during platforms operations. R\&D challenge is to upgrade algorithms and pattern detection in non-fixed scenarios. The proposed technology is also useful to enable early detection of anomalous behaviour of the wind turbine rotor.

Electrical dispatch: It is known that, when distance to shore increases, electric energy transmission may become one of the key problems for the offshore energy harvesting.

The first concern is constituted by cabling protection from hazards (risk of interaction with shipping, exposure on seabed (sand waves, scour, jagged rocks). The second point is associated to the fluctuating nature of the energy sources. These aspects add risk perception to the initial investment in grid infrastructures, cables and substations, which take the major part of offshore renewables energy projects initial costs and are often seen as the main barriers.

Whilst the first aspect can be resolved by appropriate site engineering design, the second one reserves margins for $R \& D$ endeavour. In particular, it is required that power electronics of the hybrid energy system meet quality parameters of the network (high values of Short Circuit Ratio, SCR) to sustain the direct delivery, thus limiting the need of ancillary power storage system for emergencies. The electrical subsystem design has then to balance the output voltage with distance from shore and the aggregated power (wind turbine and WECs). Two distinct electrical substations are then considered: a transformers' room on-board platform (Figure 9) and a substation on land, being this latter considered as part of the land network.

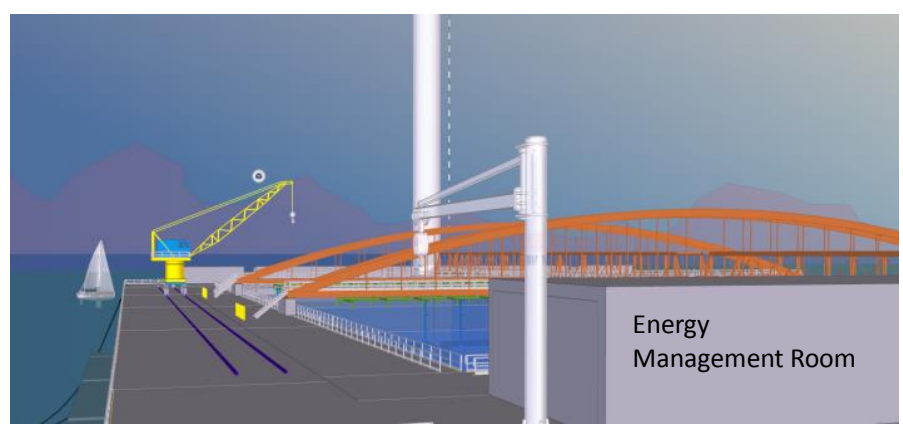

Figure 9. The Blue Growth Farm electrical substation

The following challenges are worth to be investigated to reduce costs, for both scaled \& full scale solutions: A) deviceto-cable connector: new design of the double cover protecting the cable terminals (power and data), starting from the TECNALIA patent (PCT/ES2013-070196), to make the solution sufficiently robust to resist marine environment and operations. This solution will allow: i) quick connection / disconnection operation, ii) easy disconnection in case of emergency condition (sudden bad weather), iii) programmed controlled break in case of disaster (ship or whale impact); B) dynamic umbilical cable: optimisation design to define the minimum cross section and electrical characteristics to achieve the lower voltage drop and power losses being within a cost rating. Mechanical design has to characterise lengths, bending ratio, mechanical resistance, armour type and other additional external protection devices. Effects of umbilical cable / mooring systems coupling are key aspects of the engineering design.

Shipping operations: Shipping operations are essential for offshore economic activities. Fish transportation from farm will occur by means of traditional vessel or by next generation vessels, which may accommodate hybrid or full electric propulsion and capable of automatic docking capabilities. Then, opportunity for these latter to benefit automatic connection of vessel power system to the dock power line for efficient \& safe battery recharge represents a real challenge to use the facility as a "sea electric service station". 
Logistics and platform operations: Design and sizing of logistic \& platform operations are highly dependent on platform productions systems and services, then again on the integrated systems design. Platform deck will be equipped with cranes to enable operations at aquaculture level and then to facilitate fish loading/unloading operations in health \& safety conditions. It is expected that compromises between activities must be struck to arrive at technologically feasible solutions, whilst seeking economic viability.

\section{METHODOLOGY FOR THE ENGINEERING DEVELOPMENT}

The overall target of the Blue Growth Farm project is to achieve a detailed design of the multi-purpose platform, which: 1) combines aquaculture and renewable energy production systems, 2) operates with advanced automation and remote control capabilities, 3) dispatches extra produced electric energy to the grid and provides sea electric station service to platform shipping operations. The project implementation methodology required to achieve these objectives is depicted in Figure 10. In order to reduce technical and economic risks, specific $R \& D$ challenges are expected to be resolved by carrying out experimental activities on scaled versions of the multi-purpose platform (indoor and outdoor prototypes). The physical demonstrators are designed and used at specific phases of the development timeline in order to provide suitable input to in parallel full scale engineering design development.

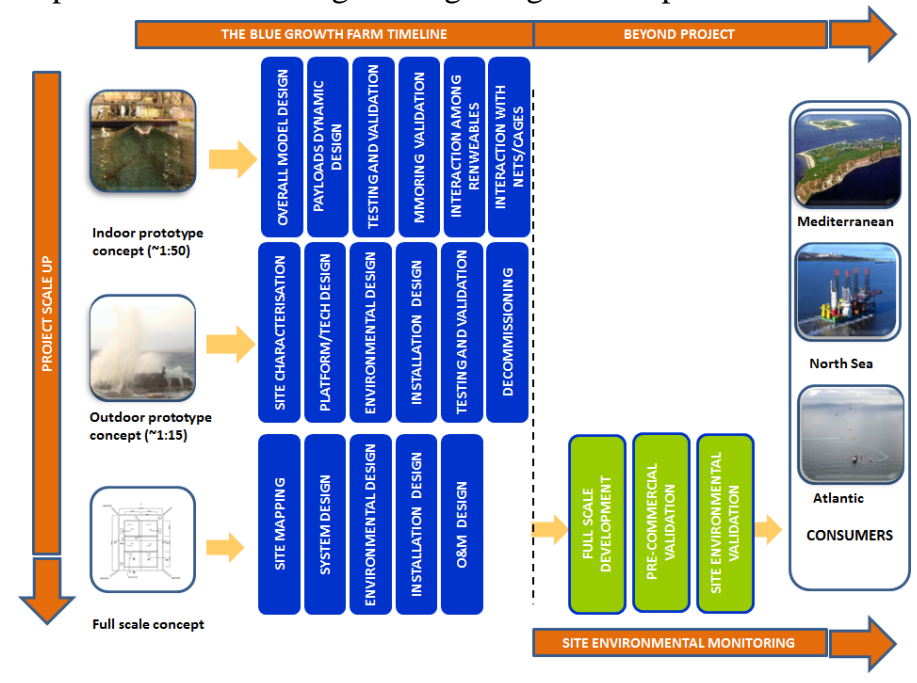

Figure 10. The Blue Growth Farm upscale development plan

Commercial relevance to the project is provided by validation of the business model and by clear assessment of environmental impacts and sustainability monitoring in the long term. These actions will support the exploitation phase beyond the end of the project, for further commercial exploitation. Potential applications are relevant to market and customers in the Mediterranean Sea, with prospects for the North Sea, which presents more favourable renewable energy sources conditions, and even technology transfer in the Atlantic areas.

\section{BGF Experimental campaign}

Suitable characterization of the proposed multipurpose platform design will be given by the experimental validation of the coupled dynamics to be carried out through an indoor prototype to be tested at the Ocean Basin wave tank, Nantes Laboratory. As well, early activity specifically addressed to evaluate the impact of the close co-location of aquaculture system with other systems of the multi-purpose platform set within the context of the cultured fish species is carried out by means of numerical models and of experimental investigation.

The outdoor prototypes, constituted by the aero/hydro scaled model, which verifies appropriateness of the full scale design and by the functional model, which validate the concrete caissons connection, will be manufactured at Fincosit srl facility, in the Port of Reggio Calabria (IT), and then transported and deployed at its final installation site, within the Natural Ocean Engineering Laboratory (NOEL) marine area. The project phase addressing use and exploitation of the outdoor prototypes follows a comprehensive up-scaling approach: i) environmental characterization of the site object of the prototype installation, ii) design of the aero/hydro scaled prototype, including integration of the selected equipment required for the experimental phase and of the functional model; iii) evaluation of impacts on the marine environment consequent to the planned activities and achievement of necessary permits; iv) design of installation, which includes mooring and seabed anchoring, implementation of safety \& security measures to enable the experimental activities, v) carrying out the envisaged experimental tests and demonstration activities; vi) prototypes decommissioning and site restoration.

The main $\mathrm{R} \& \mathrm{D}$ challenging aspects include:

- buoyancy of the selected platform shape configuration: analysis of measurement data from meteocean sensors;

- stability and dynamics of the platform fitted with the renewable energy production systems under the real wind and waves loading: combined analysis of data coming from sensors on wind turbine tower and on platform;

- interaction between the concrete platform and the aquaculture cages: analysis of data coming from sensors at the cage - structure interface and at net cage anchoring line;

- structural resistance of the aero/hydro scaled prototype under sea wind and waves loading: analysis of data from SHM and from the scaled wind tower control system;

- behaviour and loading effects on the mooring system: analysis of data coming from sensors placed at mooring chains level;

- behaviour and loading effects on the umbilical dynamic cable: analysis of data coming from sensors placed at cable/connector level;

- interaction of the mooring system with the umbilical cable: analysis of optical data (camera), data coming from sensors placed at mooring chains / cable / connector levels and from direct in situ inspection;

- testing of device-to-cable connection: proof of effective manoeuvring during connection \& disconnection operation, 
structural resistance, water-tightness and umbilical cable integrity (testing carried out with umbilical cables electrically disconnected from the generator);

- testing of surveillance and security system (long distance \& stereo cameras) and machine learning based control system.

\section{Full scale engineering design}

The full scale offshore multipurpose platform design analogously follows a comprehensive up-scaling engineering development, through: i) environmental characterization of the selected sites for the platform installation, ii) design of the overall integrated assembly of systems composing the multipurpose platform; iii) evaluation of impacts on the marine environment due to the production processes envisaged, ecosystem modelling evaluations, definition of short-long term environmental monitoring plan to add new knowledge and validate models; iv) implementation of a participatory process for social acceptance, information sharing and synergies with marine users and environmental stakeholders, including associated permitting and production acceptance by relevant involved authorities; v) design of installation, which includes mooring and seabed at envisaged location and connection to the land network; vi) design of operation and maintenance activities relating all systems of the multipurpose platform. In particular, novel concepts of integrated multipurpose offshore platform as proposed in the BGF project are the best candidate to promote new professional and skills to be trained to work in the blue economy. Training needs for operation and maintenance of the Blue Growth Farm multipurpose platform, which include automated aquaculture system, will be fully characterized, for a further validation in the full scale development.

\section{Design for economicity and sustainability}

Sustainability of the business model and associated business plan constitutes a fundamental milestone of the Blue Growth Farm project. The need to comprehensively assess costs and revenues during the entire cycle of the infrastructure life is vital to support its financiability. For this reason, in-depth LCALCC analyses are instrumental to such characterization [17]. As well, the system design will assess and monitor commercial costs of the envisaged technologies, from the complete inventory list of the platform, quantify development costs of adjustment / upgrades for the purpose of the project, establish development costs and industrialization costs of the newly equipment conceived. The overall approach proposed is expected to be instrumental in reducing risk perception to investment, and in making BGF deployment easier because of demonstrated sustainable impact on environment and improved acceptability to communities in general and to governments and sea administrations [18].

\section{Design for social acceptance}

The above mentioned participatory process for social acceptance, information sharing and synergies with marine users and environmental stakeholders, including associated permitting and production acceptance by relevant involved authorities, is part of the proposed strategy to make the Blue
Growth Farm multipurpose platform concept sustainable for potential commercial exploitation in the real market. In particular, the proposed concertation approach to multipurpose offshore platform, based on Social License to Operate (SLO) theory [19], [20], will be carried out either at the local scale (project validation and demonstration site) or at larger scale of potential full scale offshore deployments [21], [22]. Developments and licenses required for a viable enterprise involving Multipurpose Offshore Installations (MOI) are represented by (Figure 11):

- Social license, depending on i) consent resulting from Marine Spatial Planning, as governed by the Maritime Spatial Planning Framework Directive (MSPFD) and ii) SLO derived from relevant civil society.

- Environmental License, dependent on the Marine Strategy Framework Directive (MSFD), via consents and procedures derived from appropriate levels of governance.

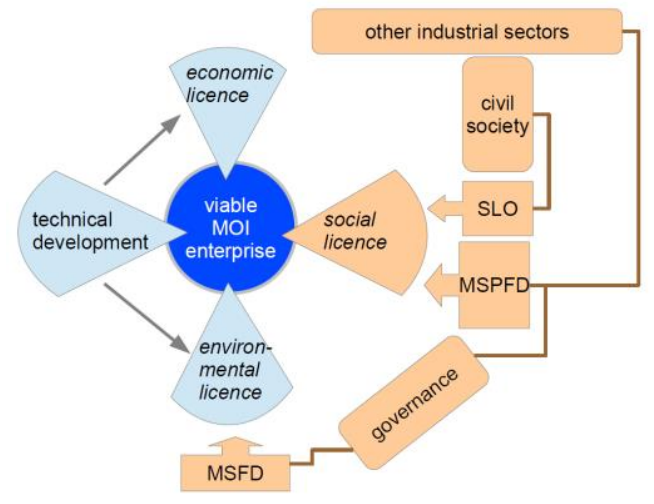

Figure 11. The Blue Growth Farm social acceptance process

The Blue Growth Farm will therefore use methods shown in Figure 12 (orange boxes) to investigate on the two components of social licence for the BGF application.

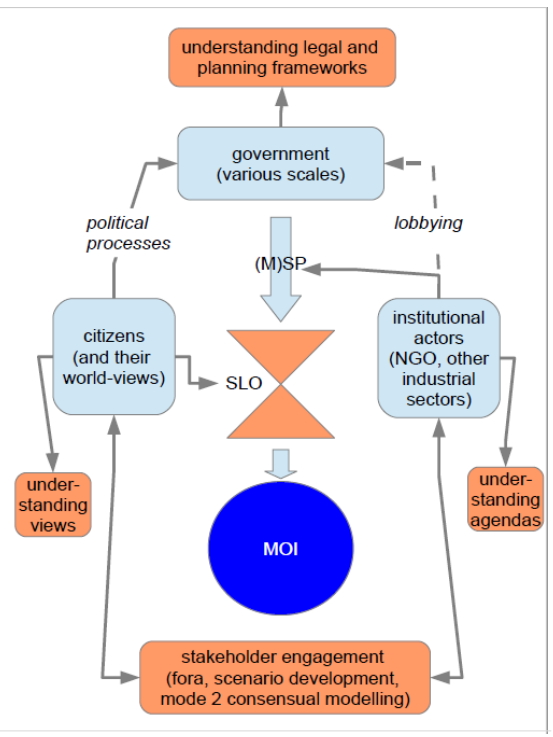

Figure 12. SLO process defined for the Blue Growth Farm project 
SLO, seen as a local property, will be studied by ascertaining the views of citizens living close to the prototype MOI, using public discourse analysis, and engaging citizens in stakeholder workshops together with institutional actors. Then, attitudes to the use of large offshore MOI will be explored through other stakeholder workshops and institutional mapping will be used to expand this diagram of the planning process.

The availability of the NOEL open sea facility represents a relevant opportunity to showcase the evolution of the project to the involved stakeholders. In particular, three workshops will be organised at different steps of the prototype design \& development \& demonstration phase: i) at project concept and site characterisation $(\mathrm{T} 0+15)$, ii) at detailed design completed $(\mathrm{T} 0+23)$, iii) during the testing and validation phase $(\mathrm{T} 0+32)$. A technical consultation is also planned to be carried out with authorities $(\mathrm{T} 0+16)$ to report on environmental issues. During the entire lifecycle a structure process of informed and participated involvement of relevant stakeholders (Figure 13) is maintained to enable eventual conflicts resolution, adequate the design to local needs and limitations, take duly care of constraints and cumulative impacts by implementing remedial actions, furnish evidence of the monitoring plan output and its correct management through time.

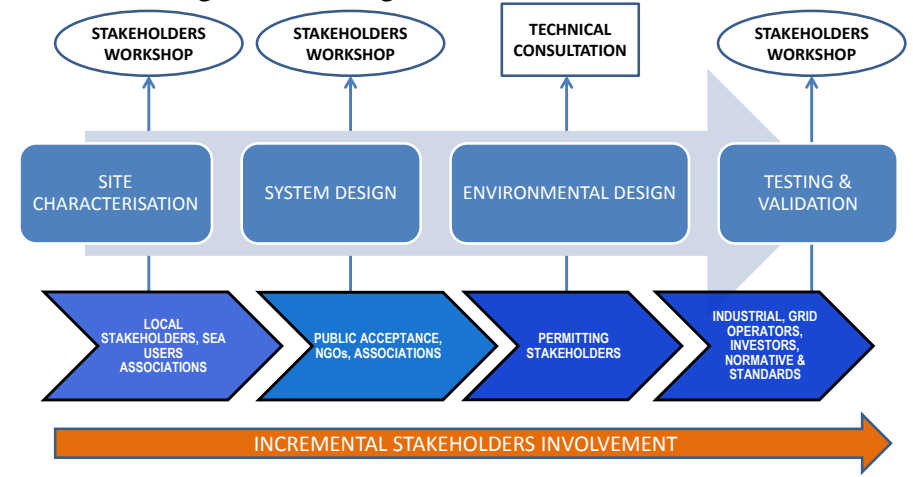

Figure 13. The Blue Growth Farm upscale stakeholders involvement

\section{CONCLUSIONS}

The development of the multi-use sea platforms concept has clearly become one of the EU's most interesting and ambitious projects in order to ensure the integrated, sustainable and ecological exploitation of open sea resources. In particular, there is increasing recognition that aquaculture can contribute to EU policies and strategies, including Blue and Green Growth and the Bioeconomy, the use of sustainable resources, food security and public health by providing sustainably produced, high quality and healthy food.

Whilst open sea farming has evident benefits, infrastructure facilities required have to undergo an innovative design and a suitable development to overcome the challenges to replace more traditional inshore fish farming facilities. Although the technology may be based on traditional cage technology farming, materials and structures must be much stronger to cope with large waves and strong currents. Difficulties in anchoring and/or submerging structures in medium/deep water is challenging as well. From the aquaculture point of view, there is the need to develop and implement greater mechanisation and automation of routine operations for maintenance and harvesting, ranging from automated feeder systems and robotic cage cleaners to long-range $\mathrm{WiFi}$ secure communications, so to promote safety and efficiency by reducing human effort and make commercial-scale open ocean farming profitable. The opportunity to combine with offshore renewables makes aquaculture energy independent and offer electric recharge possibility to O\&M hybrid propelled specialised vessels, thus opening a complete new chance of contribution to pollution decrease at sea. These are key aspects addressed by the Blue Growth Farm EC funded project with clear quantified objectives. The Blue Growth Farm concept wishes to develop a fully comprehensive system design capable to suitably exploit the aquaculture technology today available in a context of multipurpose platform combined to profitable renewable electric energy production. Technology complexity and associated costs are then balanced with reduced and common O\&M tasks, less human exposure and less risk perception thanks to greater reliance on remote monitoring, control and management capability. The Blue Growth Farm approach aims at customizing needs for a commercial size of multipurpose platform, exploiting return of experience from a comprehensive experimental campaign on indoor model in ocean basin tank and on scaled outdoor prototypes in sea environment. Training needs for operation and maintenance of the multipurpose platform, which include automated aquaculture system, will be fully characterized, for a further validation in the full scale development. The contribution expected from the project is then to clearly establish professional skills and competences of personnel operating in the blue economy industry. From the technology point of view, modularity of concrete caissons and the best practice for their connection matured in the project is expected to contribute to a $30 \%$ costs reduction with respect to built-on-place concrete breakwaters. Device-to-cable components for electrical connection to network will be tailored to the multipurpose offshore platform by using innovative adaptive solutions from existing onshore consolidated applications, such to reduce connection costs (affordability), risk for their manufacturability, and easy scalability (from prototype to full scale). Specific R\&D investigation will be deemed to employ and validate solutions based on cheaper \& standardized components for the electric umbilical cable and the device-to-cable offshore connection to network without losing in power quality level. The return of experience will result in at least $50 \%$ reduction of combined component installation and maintenance costs relative to grid connection.

\section{ACKNOWLEDGMENTS}

This work has been produced in the framework of the Blue Growth Farm project (http://www.thebluegrowthfarm.eu/), which has received funding from the European Union's Horizon 
2020 research and innovation programme under Grant Agreement number 774426. The content of the work does not report the opinion of the European Commission and reflects only the views of the author(s), including errors or omissions. The European Commission is also not liable for any use that may be made of the information contained herein.

\section{REFERENCES}

[1] Black K. and A. Hughes, 2017, "Future of the Sea: Trends in Aquaculture", Foresight - Future of the Sea Evidence Review, commissioned as part of the UK government's Foresight Future of the Sea project, July.

[2] Scientific, Technical and Economic Committee for Fisheries (STECF), 2012, "Economic Performance of the EU Aquaculture Sector (STECF-OWP-12- 03)”, JRC Scientific and Technical Reports, Edited by Jordi Guillen, Franca Contini \& Hendrik Doerner, March.

[3] National Oceanic and Atmospheric Administration (NOAA), 2015, "Marine Aquaculture Strategic Plan FY 2016-2020", February.

[4] Li L., M. Collu, A. K. Abhinav, C. Ruzzo and F. Arena, 2019, "Analysis of the Coupled Dynamics of an Offshore Floating Multi-Purpose Platform, Part A: Rigid-Body Analysis", International Conference on Offshore Mechanics and Arctic Engineering, OMAE2019-96212, Glasgow, UK.

[5] Ruzzo C., G. Failla, F. Arena, M. Collu, L. Li and A. Mariotti, 2019, "Analysis of the coupled dynamics of an offshore multi-purpose platform, part B: hydro-elastic analysis with flexible support platform", International Conference on Offshore Mechanics and Arctic Engineering, OMAE2019-96282, Glasgow, UK.

[6] Fontanella A., F. Taruffi, S. Muggiasca and M. Belloli, 2019, "Design methodology for a floating offshore wind turbine large-scale outdoor prototype", International Conference on Offshore Mechanics and Arctic Engineering, OMAE2019, Glasgow, UK.

[7] Leira B. J., 2017, "Multi-purpose Offshore Platforms: past, present and future research and developments", Proceedings of the 36th International Conference on Offshore Mechanics and Arctic Engineering, OMAE2017, June 25-30.

[8] Zanuttigh, B; Angelelli, E., Kortenhaus, A., Koca, K., Krontira, Y, Kondouri, P. (2016). A methodology for multi-criteria design of multi-use offshore platforms for marine renewable energy harvesting. Renewable Energy, 85: 1271-1289.

[9] Bak C., F. Zahle, R. Bitsche, T. Kim, A. Yde, L. C. Henriksen, A. Natarajan and M. H. Hansen, 2013, "Description of the DTU 10 MW Reference Wind Turbine", DTU Wind Energy Report-I-0092, July.

[10] Boccotti P. et al., 2007, “Caisson breakwaters embodying an OWC with a small opening. Part II: a small scale field experiment", Ocean Engineering, Volume 34, Issues 5-6, pp. $820-841$.
[11] Silva D., E. Rusu and C. G. Soares, 2018, "The Effect of a Wave Energy Farm Protecting an Aquaculture Installation", MDPI publication, Energies, 11, 2109.

[12] Chao Sun A.M., V. Jahangiri, 2018, "Integrated Vibration Control and Energy Harvesting of Offshore Wind Turbines Subjected to Misaligned Wind and Wave Loading", ResearchGate publication, April.

[13] Lemmer F., W. Yu, P. W. Cheng, 2018, "Iterative Frequency-Domain Response of Floating Offshore Wind Turbines with Parametric Drag", MDPI publication, Joirnal of marine Science and Engineering, 6, 118.

[14] Haji M. N., J. M. Kluger, T. P. Sapsis and A. H. Slocum, 2018, "A symbiotic approach to the design of offshore wind turbines with other energy harvesting systems", Ocean Engineering, Volume 169, 1 December 2018, 673681.

[15] Dominguez-Navarro J. A. and E. Tedeschi, 2016, "Evaluation of the fluid model approach for the sizing of energy storage in wind-wave energy systems", MDPI publication, Energies, 9, 162.

[16] Gao Z., T. Moan, L. Wan and C. Michailides, 2016, "Comparative numerical and experimental study of two combined wind and wave energy concepts", ScienceDirect publication, Journal of Ocean Engineering and Science, 36-51.

[17] Uihlein, 2016, "Life cycle assessment of ocean energy technologies", Int. J. Life Cycle Assess, 21:1425-1437.

[18] Wever L., G. Krause and B. H. Buck, 2015, "Lessons from stakeholder dialogues on marine aquaculture in offshore wind farms: Perceived potentials, constraints and research gaps", ScienceDirect publication, Marine Policy 51, 251259.

[19] Prno, J., 2013, "An analysis of factors leading to the establishment of a social licence to operate in the mining industry", Resources Policy 38: 577-590.

[20] Tiller, R., R. Richards, H. Salgado, H. Strand, E. Moe \& J. Ellis, 2014, “Assessing Stakeholder Adaptive Capacity to Salmon Aquaculture in Norway. Consilience: The Journal of Sustainable Development", 11(1): 62-96.

[21] Gentry R. R., S. E. Lester, C. V. Kappel, C. White, T. W. Bell, J. Stevens, S. D. Gaines, 2016, "Offshore aquaculture: spatial planning principles for sustainable development", Ecology and Evolution 2017, 7: 733-743.

[22] Marian Stuiver et al., 2016, "The Governance of MultiUse Platforms at Sea for Energy Production and Aquaculture: Challenges for Policy Makers in European Seas", MDPI publication, Sustainability 2016, 8, 333. 